\title{
Variable Phenotypes of Epilepsy, Intellectual Disability, and Schizophrenia Caused by 12p13.33-p13.32 Terminal Microdeletion in a Korean Family: A Case Report and Literature Review
}

\author{
Ji Yoon Han ${ }^{1}$ (D) and Joonhong Park $2,3, * \mathbb{D}$ \\ 1 Department of Pediatrics, College of Medicine, The Catholic University of Korea, Seoul 06591, Korea; \\ han024@catholic.ac.kr \\ 2 Department of Laboratory Medicine, Jeonbuk National University Medical School and Hospital, \\ Jeonju 54907, Korea \\ 3 Research Institute of Clinical Medicine of Jeonbuk National University-Biomedical Research Institute of \\ Jeonbuk National University Hospital, Jeonju 54907, Korea \\ * Correspondence: miziro@jbnu.ac.kr; Tel.: +82-63-250-1218
}

Citation: Han, J.Y.; Park, J. Variable Phenotypes of Epilepsy, Intellectual Disability, and Schizophrenia Caused by 12p13.33-p13.32 Terminal Microdeletion in a Korean Family: A Case Report and Literature Review. Genes 2021, 12, 1001. https://doi.org/ $10.3390 /$ genes 12071001

Academic Editor: Emiliano Giardina

Received: 3 May 2021

Accepted: 28 June 2021

Published: 29 June 2021

Publisher's Note: MDPI stays neutral with regard to jurisdictional claims in published maps and institutional affiliations.

Copyright: (c) 2021 by the authors. Licensee MDPI, Basel, Switzerland. This article is an open access article distributed under the terms and conditions of the Creative Commons Attribution (CC BY) license (https:/ / creativecommons.org/licenses/by/ $4.0 /)$.

\begin{abstract}
A simultaneous analysis of nucleotide changes and copy number variations (CNVs) based on exome sequencing data was demonstrated as a potential new first-tier diagnosis strategy for rare neuropsychiatric disorders. In this report, using depth-of-coverage analysis from exome sequencing data, we described variable phenotypes of epilepsy, intellectual disability (ID), and schizophrenia caused by 12p13.33-p13.32 terminal microdeletion in a Korean family. We hypothesized that CACNA1C and KDM5A genes of the six candidate genes located in this region were the best candidates for explaining epilepsy, ID, and schizophrenia and may be responsible for clinical features reported in cases with monosomy of the 12p13.33 subtelomeric region. On the background of microdeletion syndrome, which was described in clinical cases with mild, moderate, and severe neurodevelopmental manifestations as well as impairments, the clinician may determine whether the patient will end up with a more severe or milder end-phenotype, which in turn determines disease prognosis. In our case, the 12p13.33-p13.32 terminal microdeletion may explain the variable expressivity in the same family. However, further comprehensive studies with larger cohorts focusing on careful phenotyping across the lifespan are required to clearly elucidate the possible contribution of genetic modifiers and the environmental influence on the expressivity of $12 \mathrm{p} 13.33$ microdeletion and associated characteristics.
\end{abstract}

Keywords: variable phenotypes; 12p13.33 microdeletion; epilepsy; intellectual disability; schizophrenia; exome sequencing; chromosomal microarray; CACNA1C gene; KDM5A gene

\section{Introduction}

Developmental delay (DD) and intellectual disability (ID) are key features in patients with subtelomeric defects. Subtelomeric regions are more susceptible to aberrant alterations than other chromosomal regions and are commonly enriched for genes [1]. For example, 4p- (Wolf-Hirschhorn), 5p- (cri du chat), 9p-, 13q-, and 18p- syndromes are cases of microscopically visible deletions in the subtelomeric region, which usually cause DD or ID [2]. Although the disease and genetic association have not been well defined, subtelomeric alterations were reported as a cause of DD, ID, and multiple congenital anomalies [3,4]. In these cases, the clinical manifestations are probably determined by the type and location of the chromosomal alterations, such as duplications or deletions, as well as the size of the alterations, including the function and numbers of the genes involved [5]. Fine mapping of the subtelomeric regions has become a new strategy for identifying novel genes responsible for DD and/or ID. Constitutional deletions involving the distal part of the short arm of 
chromosome 12 (12p13.33-p13.32) are very rare and have been reported in only 28 cases so far [6-23]; either inherited $[14,15,17]$ or sporadic $[12,16,17,21,23]$ and identified by conventional karyotyping or chromosomal microarray (CMA). Notably, among the reported cases, the clinical manifestations differed substantially according to the size of the deletion. In addition, a distinct number of similar phenotypes were outlined, resulting in the proposal of a 12 p13 deletion spectrum syndrome $[13,21]$, which are generally characterized by a variable degree of behavioral problems and delayed speech or language development with or without ID. Nevertheless, several confounders in drafting a list of frequent clinical symptoms were illustrated, based on the failure to account for the size of deletions sizes and missing differences between 12p13 terminal and interstitial microdeletions. Differential haploinsufficiency of a bunch of these genes acting together is responsible for the variable phenotypes of cases with monosomy of the 12p13.33 subtelomeric region. In the last decades, comparisons of sporadic 12p13.33 microdeletions proposed a novel 12p13.33 locus that is associated with childhood speech apraxia and harbors nine genes, including ADIPOR2, CACNA1C, CACNA2D4, DCP1B, ERC1, FBXL14, LRTM2, RPS4X, and WNT5B $[12,14,17,18,22]$.

On the other hand, next-generation sequencing (NGS), including the low-coverage whole-genome sequencing (WGS) approach, is more sensitive to detecting copy number variations (CNVs) as compared with the currently commercially available chromosomal microarrays and is effective for CNV detection in clinical samples [24]. Furthermore, simultaneous analysis of nucleotide changes and CNVs based on exome sequencing data was demonstrated as a potential new first-tier strategy to diagnose rare neuropsychiatric disorders [25]. The combination of copy number variation sequencing and exome sequencing is recommended as an improved diagnostic option for cases with less obvious or otherwise undiagnosed diseases suspected to have a genetic etiology [26].

In this report, using depth-of-coverage analysis from exome sequencing data, we identified a putative 12p13.33-p13.32 terminal microdeletion in a Korean family with epilepsy, ID, and schizophrenia. We hypothesized that exome sequencing analysis and comparative genetic evaluation of reported cases with 12p13.33-p13.32 microdeletion would provide sufficient data to confirm that $C A C N A 1 C$ and $K D M 5 A$ genes of the six candidate genes located in this region were the best candidates for explaining epilepsy, ID, and schizophrenia and may be responsible for clinical features reported in cases with monosomy of the 12 p13.33 subtelomeric region.

\section{Materials and Methods}

\subsection{Exome Sequencing of the Mother-Daughter Duo}

To investigate the potential genetic cause of epilepsy, ID and/or schizophrenia in this family, the exomic DNA of the proband and her mother were enriched using Agilent's SureSelect XT Human All Exon v5 (Agilent Technologies, Santa Clara, CA, USA). Based on neuropsychiatric disorder suspicions, paired-end sequencing was conducted on the Illumina HiSeq2500 (Illumina, San Diego, CA, USA) at the Green Cross Genome (Yongin, Korea) to identify the genetic alteration. Base-calling, alignment, variant calling, annotation, and quality control reporting were performed using a GATK Best Practices workflow for germline short variant discovery (https:/ / gatk.broadinstitute.org/hc/en-us; accessed on 27 August 2020). Interpretation of sequence variants was manually reviewed by medical laboratory geneticists according to the Joint Consensus Recommendation of the American College of Medical Genetics and Genomics and the Association for Molecular Pathology standards and guidelines [27]. The filtering criteria for nucleotide changes were: Phred quality score $>20$, no Fisher strand bias, read depth $>30 \times$, allele frequency $<0.1 \%$, nonsynonymous substitution or indel occurred in coding region and exon-intron boundaries, heterozygous variant in both the mother and proband in a dominant manner, and reported to be associated with epilepsy, DD/ID, and/or schizophrenia in the OMIM database. Each of the candidate variants leading to a genetic diagnosis was visually evaluated using Integrative Genomics Viewer followed by Sanger validation. Candidate variant genes with 
predicted pathogenicity and those affecting the coding region or splice site were validated using Sanger sequencing with ABI3500XL Genetic Analyzer (Applied Biosystems, Foster City, CA, USA). Considering that unexplained DD/ID, congenital anomalies, and autism spectrum disorder (ASD) have been associated with CNV [28], an additional depth-ofcoverage analysis of exome sequencing data was performed using ExomeDepth, call CNVs from targeted sequence data [29], and VisCap, inference, and visualization of germline CNVs from targeted clinical sequencing data [30].

\subsection{Chromosomal Microarray}

To confirm the CNV identified by exome sequencing with depth-of-coverage analysis, a whole genomic screening of chromosomal rearrangements by CMA was performed using SurePrint G3 Human CGH + SNP Microarray $4 \times 180 \mathrm{~K}$ (Agilent Technologies, Santa Clara, CA, USA), according to the manufacturers' recommendation. All the samples were matched with Human Genomic DNA reference (Agilent Technologies or Promega, Madison, WI, USA). Data were obtained using the Agilent Feature Extraction software 12.0.2.2 and Agilent CytoGenomics 4.0 and visually assessed using the Agilent Genomic Workbench Software 7.0.4.0 and Agilent CytoGenomics 4.0. Genomic positions were mapped using the human genomic reference sequence GRCh37/hg19. CNVs were identified using the ADM-2 algorithm with filters of minimal absolute average log ratio of 0.25 as the cut-off, copy number neutral loss of heterozygosity regions, and minimal size of $200 \mathrm{~kb}$ in the region.

\section{Case Presentation}

The proband (III-2 in Figure 1A) was a 12-year-old girl with status epilepticus and ID, who was referred to the department of pediatric neurology, Daejeon St. Mary's Hospital (Daejeon, Korea), due to prolonged seizures. She showed generalized tonic-clonic seizure with upper eyeball deviation for $30 \mathrm{~min}$. Seizure ceased after administration of lorazepam, phenytoin, and phenobarbital. She was the second child of non-consanguineous parents, and pregnancy was uneventful. Except for the mother's history of neuropsychiatric disorder, there was no family history of neurodevelopmental diseases, including epilepsy, DD/ID, or psychiatric disorder. She had neither facial dysmorphism nor skeletal malformations on the physical examination. There was no problem during the neonatal period: She smiled at 12 weeks, sat at 10 months, crawled at 17 months, and walked independently at 24 months. Language development was profoundly delayed with first words at 3 years. She was not fully toilet trained until the age of 9 years. Standard education was interrupted before the child started primary school, and she attended a school for special-needs children. Her intellectual quotient was estimated at 60, indicating moderate ID on the Wechsler Intelligence Scale for Children-Revised. Brain magnetic resonance imaging showed a normal myelination pattern with no obvious abnormalities. Electroencephalography revealed sharp-and-slow waves on the left central regions. Visual and auditory evoked potentials were normal. Electrocardiography and echocardiogram showed normal results. Seizures were controlled phenobarbital and levetiracetam. On the other hand, the 40-year-old proband's mother (II-1 in Figure 1A) had mild ID and schizophrenia. She was the first child of healthy, non-consanguineous parents and was born at 38 weeks via Caesarean section. Her younger sister was healthy and had normal intelligence. Her physical examination results were normal without any dysmorphic features or malformation. She had difficulties schooling but did not attend a special-needs school. She was not able to achieve a high school curriculum but followed a vocational course. She worked as a clerk in a grocery store and married at 24 years old. When she was about 25 years old, she showed confused thinking, visual and auditory hallucinations. An assessment at 26 years of age confirmed schizophrenia, and she has been taking risperidone and fluoxetine. Now she does not work and lives as a housewife. She did not experience seizures during her adolescence years and early adulthood. Careful laboratory and radiology etiologic investigations were performed on the proband and her mother, and all the results were within the normal 
range. In addition, the chromosomal analysis revealed normal female karyotype, Fragile $X$ testing was negative, and metabolic laboratory test results were within the normal limits.
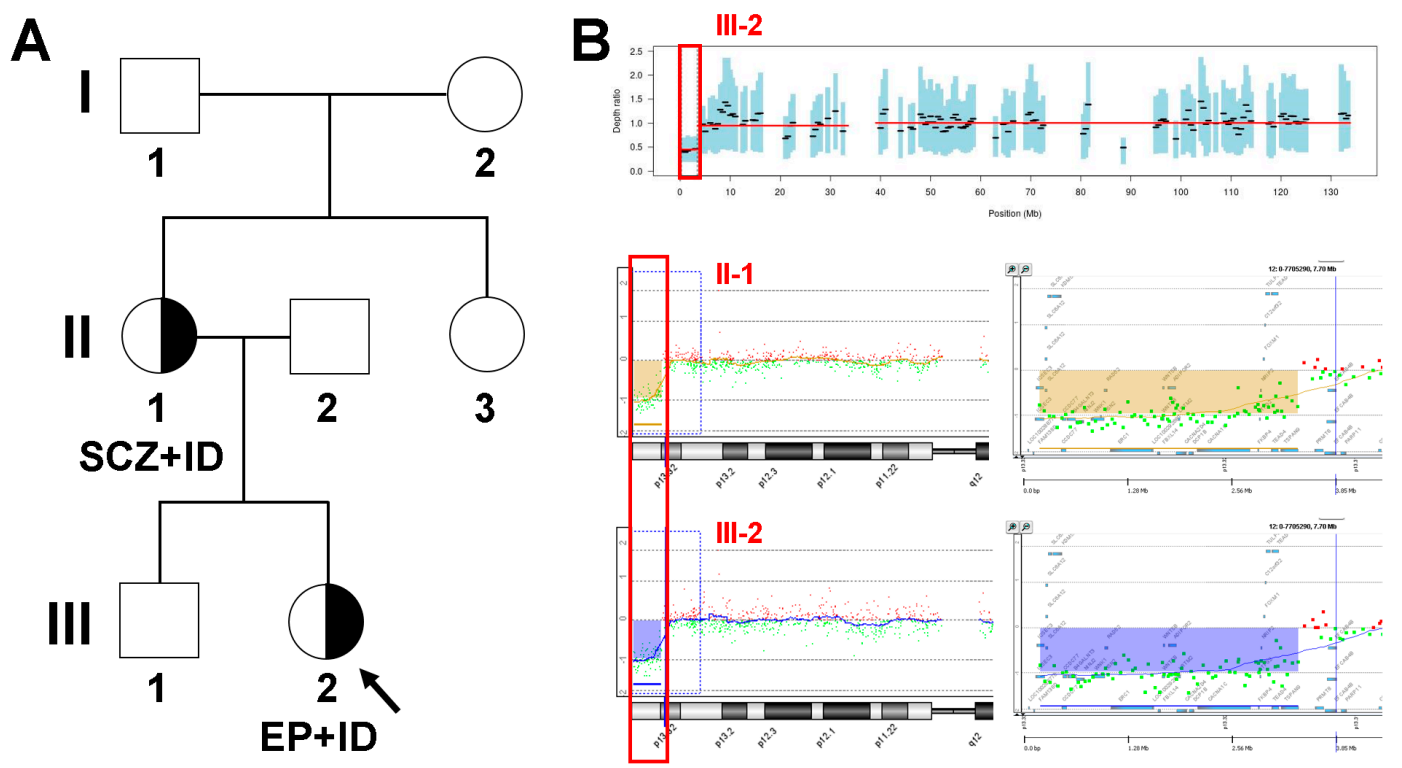

Figure 1. Pedigree analysis and coverage analysis using exome sequencing data and array-comparative genomic hybridization in the proband (III-2) and her mother (II-1). (A) Family pedigree shows a putative 12p13.33-p13.32 terminal microdeletion in a dominant manner in Korean families with epilepsy, intellectual disability, and schizophrenia. SCZ, schizophrenia; ID, intellectual disability; EP, epilepsy. (B) Results of copy number analysis using exome sequencing data and chromosomal microarray. (Upper panel) Copy number analysis using exome sequencing data detected 12p13.33-p13.32 terminal microdeletion in the proband, as highlighted in the red box. (Lower panel) Additional chromosomal microarray identified 12p13.33-p13.32 terminal microdeletion in the proband and her mother. The arr[hg19]12p13.33p13.32(230,421_3,394,129)x1 encompasses 26 genes, including IQSEC3, SLC6A12, SLC6A13, KDM5A, CCDC77, B4GALNT3, NINJ2, WNK1, RAD52, ERC1, WNT5B, FBXL14, ADIPOR2, CACNA2D4, LRTM2, DCP1B, CACNA1C, FKBP4, ITFG2, NRIP2, TEX52, FOXM1, RHNO1, TULP3, TEAD4, and TSPAN9, as highlighted in the red box.

\section{Results}

On-target yields of 3,415,455,900 and 3,386,597,831 reads were generated from the proband and her mother by estimating the sequence quality along all sequences. The mean read depths $(\times)$ were 68 and 65 , and the percentage of bases above $30 \times$ was $84 \%$ and $82 \%$, respectively. The duo exome sequencing identified no likely pathogenic variant associated with epilepsy, ID, and schizophrenia as a dominant inheritance. However, both of the CNV detection tools identified a $3.2 \mathrm{Mb}$ heterozygous deletion at chromosome 12p13.33-p13.32 with a $\mathrm{Z}$ ratio between -0.5 and -1 . As a complementary alternative method, CMA confirmed a terminal microdeletion at 12p13.33-p13.32 described as arr[hg19]12p13.33p13.32(230,421_3,394,129) $\mathrm{x}$ in the proband and her mother. This 12p13.33-p13.32 terminal microdeletion in a Korean family encompassed 26 genes, including IQSEC3, SLC6A12, SLC6A13, KDM5A, CCDC77, B4GALNT3, NINJ2, WNK1, RAD52, ERC1, WNT5B, FBXL14, ADIPOR2, CACNA2D4, LRTM2, DCP1B, CACNA1C, FKBP4, ITFG2, NRIP2, TEX52, FOXM1, RHNO1, TULP3, TEAD4, and TSPAN9. (Figure 1B).

Among 26 genes located on 12p13.33-p13.32 terminal microdeletion in a Korean family, candidate genes expected to be related to epilepsy, ID, and schizophrenia were selected according to the probability of being loss-of-function intolerant (pLI) score and gene morbidity of corresponding genes provided by DECIPHER's genome browser (https: / / decipher.sanger.ac.uk/browser\#q/12:66711-3409277/location/12:1-7952122; accessed on 11 March 2021) [31]. As a result, six candidate genes with pLI score $>0.9$ and /or gene morbidity were proposed to be associated with the clinical phenotypes in a Korean family: CACNA1C, KDM5A, WNK1, FBXL14, LRTM2, and CACNA2D4. Schematic representation 
of our patients' microdeletion, compared with previously reported cases spanning the terminal $5.5 \mathrm{Mb}$ of chromosome 12p13, was displayed by DECIPHER's genome browser (Figure 2).

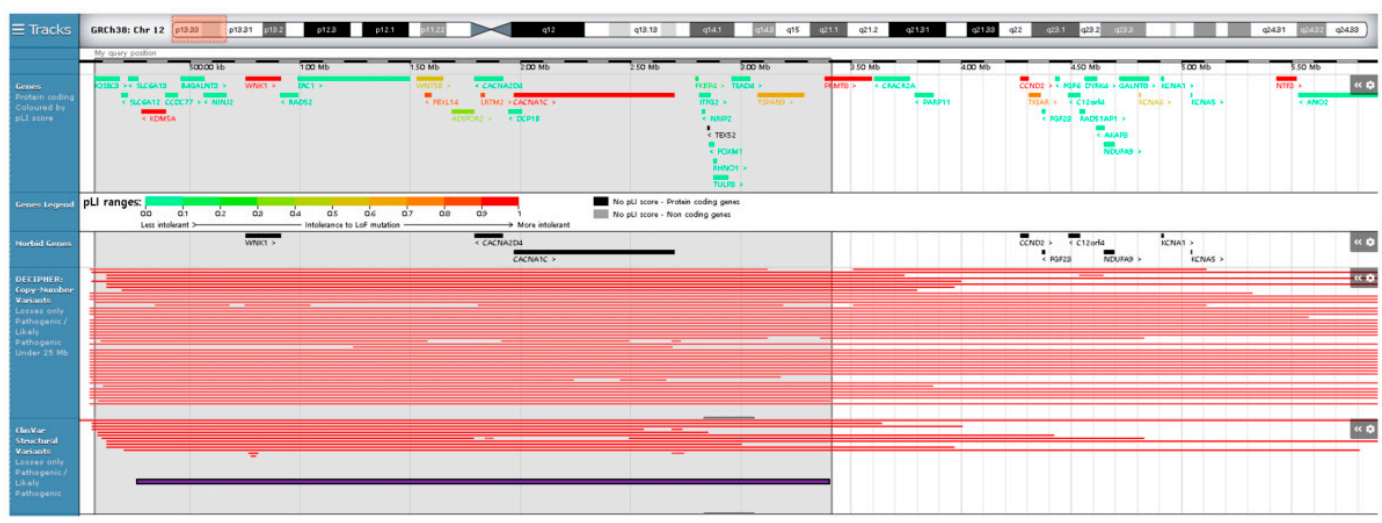

Figure 2. Schematic representation of our patient's deletion compared with the previously reported cases spanning the terminal $5.5 \mathrm{Mb}$ of chromosome 12p displayed by DECIPHER's genome browser (https:/ / decipher.sanger.ac.uk/browser\# q/12:66711-3409277/location/12:1-7952122; accessed on 11 March 2021). Red bars indicate pathogenic/like pathogenic losses under $25 \mathrm{Mb}$ by Decipher and ClinVar. Violet bar indicates 12p13.33-p13.32 identified in this study and involves six candidate genes with pLI score $>0.9$ and/or gene morbidities such as CACNA1C, KDM5A, WNK1, FBXL14, LRTM2, and CACNA2D4.

\section{Discussion}

Cytogenetically chromosomal deletions involving the distal region of chromosome 12 p13 are relatively uncommon [15]. The first case was published in 1974 with clinical manifestations including ID, atrial septal defect, microcephaly, and facial dysmorphism [6]. To date, approximately 28 reported cases with 12 p13.33 microdeletion have been described and are associated with DD/ID and various neuropsychiatric manifestations (Table 1). In these cases [6-23], the phenotypic features were variable and indistinct, maybe due to the size of the deleted segment. However, there seems to be no correlation between the size of the deleted size and the severity of the reported clinical phenotypes. Within-family discordant expressivity, age-dependent presentation, and combined functional effects of multiple haploinsufficient genes can be attributed to the reported phenotypic variability $[15,17,22]$. Nearly $60 \%$ of cases with 12 p 13.33 microdeletion had facial dysmorphism such as low-set ears, micrognathia, and slant of palpebral fissures. In the present study, approximately $30 \%$ behavioral problems incidence rate was reported in cases with $12 \mathrm{p} 13.33$ microdeletion, while schizophrenia accounted for $10 \%$ of the cases. No definite malformations were noted in non-specific dysmorphic features. Our patients showed variable clinical phenotype and disease severity, which might be partly related to a post-conceptual somatic mutation, an epigenetic change, an environmental factor, or as yet defined genetic abnormalities. Seizures were not previously described elsewhere apart from when our proband had epilepsy and was managed with two anti-seizure medications. 
Table 1. Literature review of clinical manifestations in cases with $12 p .13 .3$ microdeletions.

\begin{tabular}{|c|c|c|c|c|c|c|c|c|}
\hline Literatures & Age (yr) & Sex & $\begin{array}{l}\text { Parental Age } \\
(\mathrm{M} / \mathrm{F})\end{array}$ & Methods & Segment & Size & Clinical Manifestations & Remarks \\
\hline Mayeda (1974) [6] & 10 & $\mathrm{~F}$ & $27 / 28$ & Q-banding & del(12)p13pter & - & $\begin{array}{l}\text { Strabismus, hypoplastic mandible, large low-set ear, } \\
\text { crowed mal-aligned teeth, a funnel chest, atrial } \\
\text { septal defect, hypoplastic right lung, short } \\
\text { metacarpal bone }\end{array}$ & \multirow[t]{10}{*}{ Recurrent infections } \\
\hline Magnelli (1975) [7] & 35 & $\mathrm{M}$ & $34 / 41$ & Q-banding & del(12)p13pter & - & $\begin{array}{l}\text { Short stature, microcephaly, antimongoloid slant of } \\
\text { palpebral fissures, imperfect dental enamel, short } \\
\text { and webbed neck, short arm and short hands, } \\
\text { brachymetaphalangy, short 2nd fingers, broad } \\
\text { thumb, short metatarsal bones, big first toes }\end{array}$ & \\
\hline Kivlin (1985) [8] & 3 & $\mathrm{~F}$ & $22 /-$ & Q-banding & $\operatorname{del}(12)(\mathrm{qter} \rightarrow \mathrm{p} 12.2)$ & - & $\begin{array}{l}\text { ID, microcephaly, micrognathia, sclerocornea, } \\
\text { omphalocele, bilateral choanal atresia, simian lines, } \\
\text { clinodactyly of toes }\end{array}$ & \\
\hline Romain (1987) [9] & 3 & $\mathrm{~F}$ & $26 / 26$ & G-banding & $\operatorname{del}(12) p 13.1-p 13.3$ & - & $\begin{array}{l}\text { DD, protruding tongue, strabismus, large mouth, } \\
\text { unusual tooth, slightly micrognathia }\end{array}$ & \\
\hline Baker (2002) [10] & 15 & M & $-/-$ & G-banding, FISH & $\operatorname{del}(12) \mathrm{p} 13.33$ & $1.65 \mathrm{Mb}$ & $\begin{array}{l}\text { ID, deep-set ear, prominent ears, short neck, mild } \\
\text { thoracic kyphoscoliosis }\end{array}$ & \\
\hline Velinov (2008) [11] & 12 & $\mathrm{M}$ & $-/-$ & G-banding, CGH, FISH & $\operatorname{del}(12) p 13.3$ & $6.2 \mathrm{Mb}$ & $\begin{array}{l}\text { ID, SCZ related psychosis } \\
\text { DD, low birth weight, patent foramen ovale, short }\end{array}$ & \\
\hline Rooryck (2009) [12] & 3 & $\mathrm{~F}$ & $34 / 46$ & R-banding, CGH, qPCR & del(12)p13.33pter & $2.3 \mathrm{Mb}$ & $\begin{array}{l}\text { QT interval, microtia, preauricular tag and pit, wide } \\
\text { left corner of the mouth, left macrosomia, } \\
\text { oculoauriculovertebral spectrum }\end{array}$ & \\
\hline MacDonald (2010) [13] & 6 & $\mathrm{M}$ & $-/-$ & G-banding, MLPA, FISH & $\operatorname{del}(12) \mathrm{p} 13.3$ & $2.95 \mathrm{Mb}$ & $\begin{array}{l}\text { ID, problems with social behavior, microcephaly, } \\
\text { short nose, long face, prominent ears }\end{array}$ & \\
\hline Abdelmoity (2011) [14] & 8 & $\mathrm{~F}$ & $-/-$ & G-banding, FISH, qPCR & del(12)p13.33interstital & $1.39 \mathrm{Mb}$ & $\begin{array}{l}\text { DD, attention-deficit hyperactivity disorder } \\
\text { DD, global hypotonia, facial dysmorphism }\end{array}$ & \\
\hline Case 1 in Madrigal (2012) [15] & 8 & $\mathrm{M}$ & $-/-$ & FISH, CGH & $\mathrm{t}(12 ; 22)(\mathrm{p} 13.3 ;$ pter $)$ & $6 \mathrm{Mb}$ & $\begin{array}{l}\text { (rominent forehead, elongated face, bulbous nose } \\
\text { with broad nasal root, small mouth and thin } \\
\text { vermillion, mild hypertelorism and bilateral low-set } \\
\text { ears with over-folded helices), ID, ADHD }\end{array}$ & \\
\hline Case 2 in Madrigal (2012) [15] & 27 & $\mathrm{~F}$ & $-/-$ & FISH, CGH & $\mathrm{t}(12 ; 22)(\mathrm{p} 13.3 ;$ pter $)$ & $6 \mathrm{Mb}$ & $\begin{array}{l}\text { DD, microcephaly, facial dysmorphism, ADHD } \\
\text { ID, psychotic disorder with hallucinations, arching }\end{array}$ & \multirow[t]{3}{*}{ Maternal aunt of Case 1} \\
\hline Vargas (2012) [16] & 12 & $\mathrm{~F}$ & $25 / 35$ & G-banding, FISH, CGH & $\operatorname{del}(12) p 13.33-p 13.32$ & $4.5 \mathrm{Mb}$ & $\begin{array}{l}\text { eyebrow, malocculusion, gum hypertrophy, long } \\
\text { and curving fingers, hypermobile joints }\end{array}$ & \\
\hline Case 1 in Thevenon (2013) [17] & 3 & $\mathrm{M}$ & $35 /-$ & CGH, qPCR & del(12)p13.33-p13.32 & $3.2 \mathrm{Mb}$ & $\begin{array}{l}\text { DD, macrocephaly, coarse face, mild frontal bossing, } \\
\text { enophalmia, low-set ear, marked philtrum, large } \\
\text { nares, thin upper lip, irregular and narrowly spaced } \\
\text { teeth }\end{array}$ & \\
\hline Case 2 in Thevenon (2013) [17] & 35 & $\mathrm{~F}$ & $-/-$ & $\mathrm{CGH}, \mathrm{qPCR}$ & del(12)p13.33-p13.32 & $3.2 \mathrm{Mb}$ & Speech delay & \multirow[t]{2}{*}{ Mother of Case 1} \\
\hline Case 3 in Thevenon (2013) [17] & 5 & M & $-/ 37$ & G-banding, CGH, FISH & $\operatorname{del}(12) p 13.33$ & $1.3 \mathrm{Mb}$ & $\begin{array}{l}\mathrm{DD} \text {, ID, behavioral abnormalities (hyperactivity, } \\
\text { anxiety, solitariness, low social interaction) }\end{array}$ & \\
\hline $\begin{array}{l}\text { Case } 4 \text { in Thevenon (2013) [17] } \\
\text { Case } 5 \text { in Thevenon (2013) [17] }\end{array}$ & $\begin{array}{l}37 \\
67\end{array}$ & $\begin{array}{l}\mathrm{M} \\
\mathrm{M}\end{array}$ & $\begin{array}{l}-/ 67 \\
-/-\end{array}$ & $\begin{array}{l}\text { CGH, FISH } \\
\text { CGH, FISH }\end{array}$ & $\begin{array}{l}\operatorname{del}(12) \mathrm{p} 13.33 \\
\operatorname{del}(12) \mathrm{p} 13.33\end{array}$ & $\begin{array}{l}1.3 \mathrm{Mb} \\
1.3 \mathrm{Mb}\end{array}$ & $\begin{array}{l}\text { Speech delay } \\
\text { Speech delay, mild ID }\end{array}$ & \multirow{2}{*}{$\begin{array}{l}\text { Father of Case } 3 \\
\text { Grandfather of Case } 3 \\
\text { Preterm birth, low birth } \\
\text { weight }\end{array}$} \\
\hline Case 6 in Thevenon (2013) [17] & 10 & M & $-/-$ & CGH, FISH & $\operatorname{del}(12) p 13.33$ & $3.1 \mathrm{Mb}$ & DD & \\
\hline
\end{tabular}


Table 1. Cont.

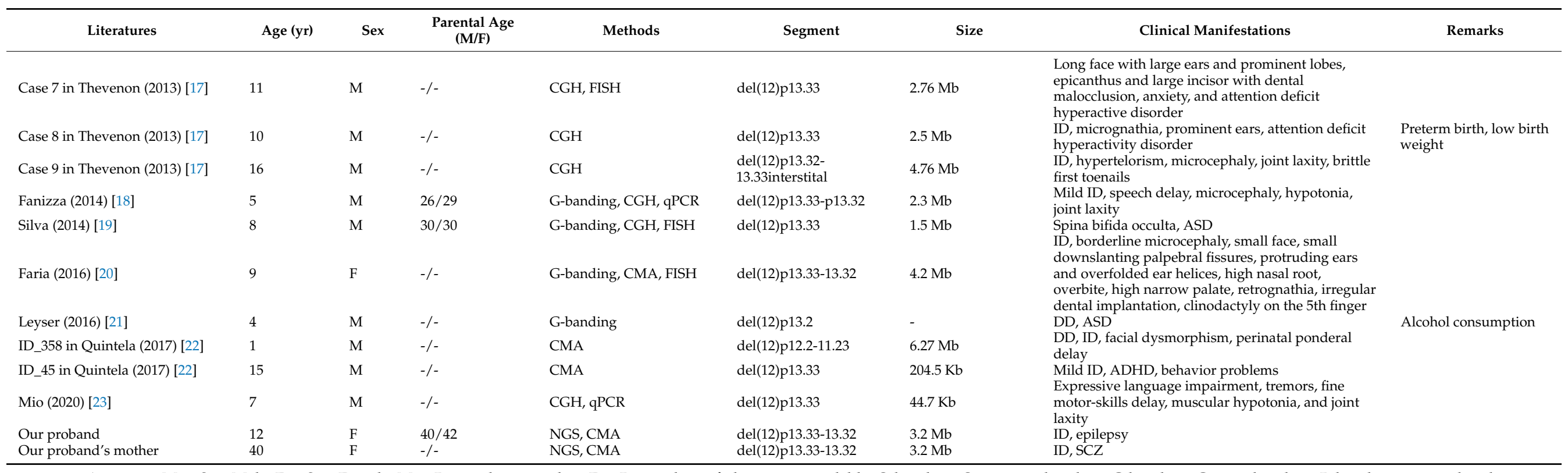

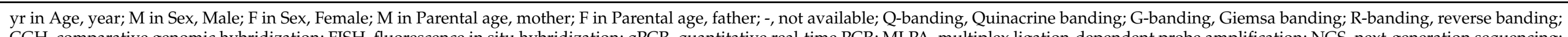

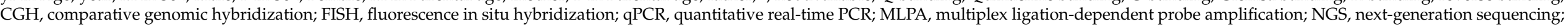
CMA, chromosomal microarray; ID, intellectual disability; DD, developmental delay; SCZ, schizophrenia; ASD, autism spectrum disorder. 
The 12p13 subtelomeric region is not a gene-abundant region and has about 35 genes spanning the four telomeric megabases. Of the six candidate genes located in this region, CACNA1C and KDM5A genes were the best candidates for explaining epilepsy, ID, and schizophrenia in a Korean family. The CACNA1C gene encodes the alpha-1 subunit of L-type voltage-dependent calcium channel (as known as Cav1.2) that is widely expressed in the brain (predominantly in the hippocampus, thalamus, and cerebral cortex) [32]. The Cav1.2 channel plays a part in neurotransmitter release, synaptogenesis, and neuronal excitability; therefore, mutation of $C A C N A 1 C$ is a possible cause of neuropsychiatric disorders [33]. Recently, the CACNA1C haploinsufficiency was reported to be responsible for the common features of interstitial 12p13.33 deletion carriers [23]. Furthermore, rs1006737 or the CACNA1C and rs1344706 ZNF804A were commonly associated with schizophrenia and bipolar disorder, and recently with brain phenotypes. For instance, CACNA1C up-regulation in schizophrenia and bipolar disorder parietal cortices [33] and implication of $C A C N 1 C$ variants in Timothy syndrome, depression, schizophrenia, bipolar disorder, and impairment of working memory and verbal fluency [34,35]. The CACN1C has potential pathogenicity in corresponding epilepsy [36]; two families with CACNA1C mutation were presented with neonatal epileptic encephalopathy and/or epilepsy combined DD/ID [37]. The CACNA1C could in part explain clinical manifestations in our proband [38], therefore we propose $C A C N 1 C$ as a new candidate gene contributing to epilepsy, ID, and schizophrenia. A detailed molecular analysis of CACN1C transcripts is required to establish its functional role in the neurotransmission process and its etiological association with neuropsychiatric disabilities.

On the other hand, mutations in several genes coding for epigenetic modulators and chromatin remodelers were associated with neurodevelopmental diseases such as ASD [39,40]. Among them, the KDM5A gene encodes a chromatin regulator, which belongs to the KDM5 family of lysine-specific histone H3 demethylases. Histone H3 lysine 4 trimethyl (H3K4me3) marks are present at active enhancers and gene promoters and are regulated by multiple factors such as the KDM5 family members KDM5B and KDM5C [41]. Mutations in lysine demethylases regulating the demethylation of the H3K4me3 marks were associated strongly with a host of neurodevelopmental diseases. Two genes of the $K D M 5 B$ and $K D M 5 C$ in the KDM5 family are disrupted in neurodevelopmental diseases such as ASD and ID [42-44]. Thus, mutations in KDM5A, KDM5B, and KDM5C lead to neurodevelopmental diseases, indicates that their function in the brain is essential. Particularly, KDM5A demethylates H3K4me3, a histone mark known to be associated with memory retrieval [45] and memory formation [46]. Several pathogenic KDM5A mutations were reported previously in patients with ASD, in conjunction with lack of speech, DD, and/or ID. Despite the phenotypic diversity observed commonly within the different genetic subtypes of ASD, all the patients with KDM5A mutations reported in a recent study show a complete absence of speech, suggesting a critical role for KDM5A in regulating verbal communication [47]. Perturbations in histone demethylases and methyltransferases at this mark give rise to neurodevelopmental diseases, including ID and ASD [48], emphasizing the significance of H3K4me3 in memory and learning.

Interestingly, CNV analysis based on the NGS approach could show several unrelated phenotypes together simply as the result of the probabilistic occurrence. Disease phenotypes mainly led to a single driver alteration, which mostly determines the diagnosis, but amelioration or exacerbation by epistatic effects is expected. On the background of microdeletion syndrome, which was described in clinical cases with mild, moderate, and severe neurodevelopmental manifestations as well as impairments, the clinician may determine whether the patient will end up with a more severe or milder end-phenotype that variably determine disease prognosis [49]. In our case, the 12p13.33-p13.32 terminal microdeletion may explain the variable expressivity in the same family. The physician should be aware that seizures and neuropsychiatric problems may occur with age in children with 12p13.33-p13.32 deletion. A better understanding of the functional consequence of 12p13.33-p13.32 deletion is needed for the targeted medicinal and non-medicinal therapy. 


\section{Conclusions}

In the present study, we identified variable phenotypes of epilepsy, ID, and schizophrenia caused by 12p13.33-p13.32 terminal microdeletion in a Korean family. Based on our findings, we propose that the haploinsufficiency of protein-coding genes might have a cardinal role in all the common characteristic phenotypes, such as expressive language delay, because these genes are have been reported to be entirely deleted in cases of 12 p13.33 microdeletions or located in diverse deletion breakpoint loci. However, further comprehensive studies with larger cohorts focusing on careful phenotyping across the lifespan are required to clearly elucidate the possible contribution of genetic modifiers and the environmental influence on the expressivity of $12 \mathrm{p} 13.33$ microdeletion and associated characteristics.

Author Contributions: Conceptualization, J.Y.H.; Data curation, J.Y.H.; Formal analysis, J.Y.H., and J.P.; Writing—original draft preparation, J.Y.H.; Writing—review and editing, J.P.; Supervision, J.P.; Funding acquisition, J.Y.H., and J.P. All authors have read and agreed to the published version of the manuscript.

Funding: This work was supported by the National Research Foundation of Korea (NRF) grant funded by the Korean government (MSIT; 2020R1F1A1077316) and the Catholic University of Korea Daejeon St. Mary's Hospital, Clinical Institute of Korea Daejeon St. Mary's Hospital (CMCDJ-P-2021-001).

Institutional Review Board Statement: This study was approved by the Daejeon St. Mary's Hospital, The Catholic University of Korea institutional review board (Approval number: DC18ZESI0047; Date of approval: 30 April 2018).

Informed Consent Statement: The participant and the parents provided written informed consent for clinical and molecular analyses. Patient consent for publication of medical information was obtained from the participants' parents.

Data Availability Statement: The data presented in this study are available on request from the corresponding author.

Acknowledgments: This study makes use of data generated by the DECIPHER community. A full list of centres who contributed to the generation of the data is available from https:// deciphergenomics. org/about/stats (accessed on 11 March 2021) and via email from contact@deciphergenomics.org. Funding for the DECIPHER project was provided by Wellcome.

Conflicts of Interest: The authors declare no conflict of interest.

\section{References}

1. Rodríguez, L.; Martínez-Fernández, M.L.; Mansilla, E.; Mendioroz, J.; Arteaga, R.M.; Toral, J.F.; Guardia, N.M.; García, A.; Centeno, F.; Pantoja, J.; et al. Screening for subtelomeric chromosome alteration in a consecutive series of newborns with congenital defects. Clin. Dysmorphol. 2008, 17, 5-12. [CrossRef] [PubMed]

2. De Vries, B.B.; Winter, R.; Schinzel, A.; van Ravenswaaij-Arts, C. Telomeres: A diagnosis at the end of the chromosomes. J. Med. Genet. 2003, 40, 385-398. [CrossRef] [PubMed]

3. Hélias-Rodzewicz, Z.; Bocian, E.; Stankiewicz, P.; Obersztyn, E.; Kostyk, E.; Jakubów-Durska, K.; Kutkowska-Kaźmierczak, A.; Mazurczak, T. Subtelomeric rearrangements detected by FISH in three of 33 families with idiopathic mental retardation and minor physical anomalies. J. Med. Genet. 2002, 39, e53. [CrossRef] [PubMed]

4. Shaw-Smith, C.; Redon, R.; Rickman, L.; Rio, M.; Willatt, L.; Fiegler, H.; Firth, H.; Sanlaville, D.; Winter, R.; Colleaux, L.; et al. Microarray based comparative genomic hybridisation (array-CGH) detects submicroscopic chromosomal deletions and duplications in patients with learning disability/mental retardation and dysmorphic features. J. Med. Genet. 2004, 41, 241-248. [CrossRef] [PubMed]

5. Wu, Y.; Ji, T.; Wang, J.; Xiao, J.; Wang, H.; Li, J.; Gao, Z.; Yang, Y.; Cai, B.; Wang, L.; et al. Submicroscopic subtelomeric aberrations in Chinese patients with unexplained developmental delay/mental retardation. BMC Med. Genet. 2010, 11, 72. [CrossRef]

6. Mayeda, K.; Weiss, L.; Lindahl, R.; Dully, M. Localization of the human lactate dehydrogenase B gene on the short arm of chromosome 12. Am. J. Hum. Genet. 1974, 26, 59-64. [PubMed]

7. Magnelli, N.C.; Therman, E. Partial 12p deletion: A cause for a mental retardation, multiple congenital abnormality syndrome. J. Med. Genet. 1975, 12, 105-108. [CrossRef] [PubMed]

8. Kivlin, J.D.; Fineman, R.M.; Williams, M.S. Phenotypic variation in the del(12p) syndrome. Am. J. Med. Genet. 1985, 22, 769-779. [CrossRef] 
9. $\quad$ Romain, D.R.; Goldsmith, J.; Columbano-Green, L.M.; Chapman, C.J.; Smythe, R.H.; Parfitt, R.G. Partial monosomy 12p13.1-13.3. J. Med. Genet. 1987, 24, 434-436. [CrossRef]

10. Baker, E.; Hinton, L.; Callen, D.F.; Haan, E.A.; Dobbie, A.; Sutherland, G.R. A familial cryptic subtelomeric deletion 12p with variable phenotypic effect. Clin. Genet. 2002, 61, 198-201. [CrossRef]

11. Velinov, M.; Beldia, G.; Gu, H.; Tsiouris, J.A.; Jenkins, E.C.; Brown, W.T. Psychotic manifestations in a patient with mental retardation and a 6.2 megabase deletion at the distal short arm of chromosome 12. CNS Spectr. 2008, 13, 515-519. [CrossRef] [PubMed]

12. Rooryck, C.; Stef, M.; Burgelin, I.; Simon, D.; Souakri, N.; Thambo, J.B.; Chateil, J.F.; Lacombe, D.; Arveiler, B. 2.3 Mb terminal deletion in 12p13.33 associated with oculoauriculovertebral spectrum and evaluation of WNT5B as a candidate gene. Eur. J. Med. Genet. 2009, 52, 446-449. [CrossRef] [PubMed]

13. Macdonald, A.H.; Rodríguez, L.; Aceña, I.; Martínez-Fernández, M.L.; Sánchez-Izquierdo, D.; Zuazo, E.; Martínez-Frías, M.L. Subtelomeric deletion of 12p: Description of a third case and review. Am. J. Med. Genet. A 2010, 152a, 1561-1566. [CrossRef] [PubMed]

14. Abdelmoity, A.T.; Hall, J.J.; Bittel, D.C.; Yu, S. 1.39 Mb inherited interstitial deletion in 12p13.33 associated with developmental delay. Eur. J. Med. Genet. 2011, 54, 198-203. [CrossRef] [PubMed]

15. Madrigal, I.; Martinez, M.; Rodriguez-Revenga, L.; Carrió, A.; Milà, M. 12p13 rearrangements: 6 Mb deletion responsible for ID/MCA and reciprocal duplication without clinical responsibility. Am. J. Med. Genet. A 2012, 158a, 1071-1076. [CrossRef] [PubMed]

16. Vargas, H.; Beldia, G.; Korosh, W.; Sudhalter, V.; Iqbal, A.; Sanchez-Lacay, J.A.; Velinov, M. A 4.5 Mb terminal deletion of chromosome 12p helps further define a psychosis-associated locus. Eur. J. Med. Genet. 2012, 55, 573-576. [CrossRef] [PubMed]

17. Thevenon, J.; Callier, P.; Andrieux, J.; Delobel, B.; David, A.; Sukno, S.; Minot, D.; Mosca Anne, L.; Marle, N.; Sanlaville, D.; et al. 12p13.33 microdeletion including ELKS/ERC1, a new locus associated with childhood apraxia of speech. Eur. J. Med. Genet. 2013, 21, 82-88. [CrossRef]

18. Fanizza, I.; Bertuzzo, S.; Beri, S.; Scalera, E.; Massagli, A.; Sali, M.E.; Giorda, R.; Bonaglia, M.C. Genotype-phenotype relationship in a child with $2.3 \mathrm{Mb}$ de novo interstitial 12p13.33-p13.32 deletion. Eur. J. Med. Genet. 2014, 57, 334-338. [CrossRef]

19. Silva, I.M.; Rosenfeld, J.; Antoniuk, S.A.; Raskin, S.; Sotomaior, V.S. A 1.5Mb terminal deletion of $12 \mathrm{p}$ associated with autism spectrum disorder. Gene 2014, 542, 83-86. [CrossRef]

20. Faria, R.S.; de Oliveira, C.P.; da Costa, M.M.; da, S.R.M.T.; Córdoba, M.S.; Pic-Taylor, A.; Ferrari, I.; de Oliveira, S.F.; Mazzeu, J.F. Concurrent Loss of Heterozygosity and Mosaic Deletion of 12p13.32pter. Cytogenet Genome Res. 2016, 148, 174-178. [CrossRef]

21. Leyser, M.; Dias, B.L.; Coelho, A.L.; Vasconcelos, M.; Nascimento, O.J. 12p deletion spectrum syndrome: A new case report reinforces the evidence regarding the potential relationship to autism spectrum disorder and related developmental impairments. Mol. Cytogenet. 2016, 9, 75. [CrossRef]

22. Quintela, I.; Eirís, J.; Gómez-Lado, C.; Pérez-Gay, L.; Dacruz, D.; Cruz, R.; Castro-Gago, M.; Míguez, L.; Carracedo, Á.; Barros, F. Copy number variation analysis of patients with intellectual disability from North-West Spain. Gene 2017, 626, 189-199. [CrossRef] [PubMed]

23. Mio, C.; Passon, N.; Baldan, F.; Bregant, E.; Monaco, E.; Mancini, L.; Demori, E.; Damante, G. CACNA1C haploinsufficiency accounts for the common features of interstitial 12p13.33 deletion carriers. Eur. J. Med. Genet. 2020, 63, 103843. [CrossRef] [PubMed]

24. Zhou, B.; Ho, S.S.; Zhang, X.; Pattni, R.; Haraksingh, R.R.; Urban, A.E. Whole-genome sequencing analysis of CNV using low-coverage and paired-end strategies is efficient and outperforms array-based CNV analysis. J. Med. Genet. 2018, 55, 735-743. [CrossRef] [PubMed]

25. Dong, X.; Liu, B.; Yang, L.; Wang, H.; Wu, B.; Liu, R.; Chen, H.; Chen, X.; Yu, S.; Chen, B.; et al. Clinical exome sequencing as the first-tier test for diagnosing developmental disorders covering both CNV and SNV: A Chinese cohort. J. Med. Genet. 2020, 57, 558-566. [CrossRef] [PubMed]

26. Jiao, Q.; Sun, H.; Zhang, H.; Wang, R.; Li, S.; Sun, D.; Yang, X.A.; Jin, Y. The combination of whole-exome sequencing and copy number variation sequencing enables the diagnosis of rare neurological disorders. Clin. Genet. 2019, 96, 140-150. [CrossRef] [PubMed]

27. Richards, S.; Aziz, N.; Bale, S.; Bick, D.; Das, S.; Gastier-Foster, J.; Grody, W.W.; Hegde, M.; Lyon, E.; Spector, E.; et al. Standards and guidelines for the interpretation of sequence variants: A joint consensus recommendation of the American College of Medical Genetics and Genomics and the Association for Molecular Pathology. Genet. Med. 2015, 17, 405-424. [CrossRef] [PubMed]

28. Jang, W.; Kim, Y.; Han, E.; Park, J.; Chae, H.; Kwon, A.; Choi, H.; Kim, J.; Son, J.O.; Lee, S.J.; et al. Chromosomal Microarray Analysis as a First-Tier Clinical Diagnostic Test in Patients With Developmental Delay/Intellectual Disability, Autism Spectrum Disorders, and Multiple Congenital Anomalies: A Prospective Multicenter Study in Korea. Ann. Lab. Med. 2019, 39, $299-310$. [CrossRef] [PubMed]

29. Ellingford, J.M.; Campbell, C.; Barton, S.; Bhaskar, S.; Gupta, S.; Taylor, R.L.; Sergouniotis, P.I.; Horn, B.; Lamb, J.A.; Michaelides, M.; et al. Validation of copy number variation analysis for next-generation sequencing diagnostics. Eur. J. Hum. Genet. 2017, 25, 719-724. [CrossRef] [PubMed] 
30. Pugh, T.J.; Amr, S.S.; Bowser, M.J.; Gowrisankar, S.; Hynes, E.; Mahanta, L.M.; Rehm, H.L.; Funke, B.; Lebo, M.S. VisCap: Inference and visualization of germ-line copy-number variants from targeted clinical sequencing data. Genet. Med. 2016, 18, 712-719. [CrossRef] [PubMed]

31. Firth, H.V.; Richards, S.M.; Bevan, A.P.; Clayton, S.; Corpas, M.; Rajan, D.; Van Vooren, S.; Moreau, Y.; Pettett, R.M.; Carter, N.P. DECIPHER: Database of Chromosomal Imbalance and Phenotype in Humans Using Ensembl Resources. Am. J. Hum. Genet. 2009, 84, 524-533. [CrossRef]

32. Napolitano, C.; Antzelevitch, C. Phenotypical manifestations of mutations in the genes encoding subunits of the cardiac voltage-dependent L-type calcium channel. Circ. Res. 2011, 108, 607-618. [CrossRef] [PubMed]

33. Tecelão, D.; Mendes, A.; Martins, D.; Fu, C.; Chaddock, C.A.; Picchioni, M.M.; McDonald, C.; Kalidindi, S.; Murray, R.; Prata, D.P. The effect of psychosis associated CACNA1C, and its epistasis with ZNF804A, on brain function. Genes. Brain. Behav. 2019, 18, e12510. [CrossRef]

34. Bigos, K.L.; Mattay, V.S.; Callicott, J.H.; Straub, R.E.; Vakkalanka, R.; Kolachana, B.; Hyde, T.M.; Lipska, B.K.; Kleinman, J.E.; Weinberger, D.R. Genetic variation in CACNA1C affects brain circuitries related to mental illness. Arch. Gen. Psychiatry. 2010, 67, 939-945. [CrossRef]

35. McGrath, L.M.; Cornelis, M.C.; Lee, P.H.; Robinson, E.B.; Duncan, L.E.; Barnett, J.H.; Huang, J.; Gerber, G.; Sklar, P.; Sullivan, P.; et al. Genetic predictors of risk and resilience in psychiatric disorders: A cross-disorder genome-wide association study of functional impairment in major depressive disorder, bipolar disorder, and schizophrenia. Am. J. Med. Genet. B. Neuropsychiatr. Genet. 2013, 162b, 779-788. [CrossRef]

36. Borlot, F.; Regan, B.M.; Bassett, A.S.; Stavropoulos, D.J.; Andrade, D.M. Prevalence of Pathogenic Copy Number Variation in Adults With Pediatric-Onset Epilepsy and Intellectual Disability. JAMA. Neurol. 2017, 74, 1301-1311. [CrossRef] [PubMed]

37. Bozarth, X.; Dines, J.N.; Cong, Q.; Mirzaa, G.M.; Foss, K.; Lawrence Merritt, J., 2nd; Thies, J.; Mefford, H.C.; Novotny, E. Expanding clinical phenotype in CACNA1C related disorders: From neonatal onset severe epileptic encephalopathy to late-onset epilepsy. Am. J. Med. Genet. A 2018, 176, 2733-2739. [CrossRef]

38. Menezes, P.R.; Lewis, G.; Rasmussen, F.; Zammit, S.; Sipos, A.; Harrison, G.L.; Tynelius, P.; Gunnell, D. Paternal and maternal ages at conception and risk of bipolar affective disorder in their offspring. Psychol. Med. 2010, 40, 477-485. [CrossRef]

39. Turner, T.N.; Hormozdiari, F.; Duyzend, M.H.; McClymont, S.A.; Hook, P.W.; Iossifov, I.; Raja, A.; Baker, C.; Hoekzema, K.; Stessman, H.A.; et al. Genome Sequencing of Autism-Affected Families Reveals Disruption of Putative Noncoding Regulatory DNA. Am. J. Hum. Genet. 2016, 98, 58-74. [CrossRef]

40. Turner, T.N.; Eichler, E.E. The Role of De Novo Noncoding Regulatory Mutations in Neurodevelopmental Disorders. Trends Neurosci. 2019, 42, 115-127. [CrossRef] [PubMed]

41. Shen, H.; Xu, W.; Lan, F. Histone lysine demethylases in mammalian embryonic development. Exp. Mol. Med. 2017, 49, e325. [CrossRef] [PubMed]

42. De Rubeis, S.; He, X.; Goldberg, A.P.; Poultney, C.S.; Samocha, K.; Cicek, A.E.; Kou, Y.; Liu, L.; Fromer, M.; Walker, S.; et al. Synaptic, transcriptional and chromatin genes disrupted in autism. Nature 2014, 515, 209-215. [CrossRef]

43. Iossifov, I.; O’Roak, B.J.; Sanders, S.J.; Ronemus, M.; Krumm, N.; Levy, D.; Stessman, H.A.; Witherspoon, K.T.; Vives, L.; Patterson, K.E.; et al. The contribution of de novo coding mutations to autism spectrum disorder. Nature 2014, 515, 216-221. [CrossRef]

44. Zhou, J.; Park, C.Y.; Theesfeld, C.L.; Wong, A.K.; Yuan, Y.; Scheckel, C.; Fak, J.J.; Funk, J.; Yao, K.; Tajima, Y.; et al. Whole-genome deep-learning analysis identifies contribution of noncoding mutations to autism risk. Nat. Genet. 2019, 51, 973-980. [CrossRef] [PubMed]

45. Webb, W.M.; Sanchez, R.G.; Perez, G.; Butler, A.A.; Hauser, R.M.; Rich, M.C.; O’Bierne, A.L.; Jarome, T.J.; Lubin, F.D. Dynamic association of epigenetic H3K4me3 and DNA 5hmC marks in the dorsal hippocampus and anterior cingulate cortex following reactivation of a fear memory. Neurobiol Learn Mem. 2017, 142, 66-78. [CrossRef]

46. Collins, B.E.; Sweatt, J.D.; Greer, C.B. Broad domains of histone 3 lysine 4 trimethylation are associated with transcriptional activation in CA1 neurons of the hippocampus during memory formation. Neurobiol Learn Mem. 2019, 161, 149-157. [CrossRef]

47. El Hayek, L.; Tuncay, I.O.; Nijem, N.; Russell, J.; Ludwig, S.; Kaur, K.; Li, X.; Anderton, P.; Tang, M.; Gerard, A.; et al. KDM5A mutations identified in autism spectrum disorder using forward genetics. Elife 2020, 9, e56883. [CrossRef]

48. Vallianatos, C.N.; Iwase, S. Disrupted intricacy of histone H3K4 methylation in neurodevelopmental disorders. Epigenomics 2015, 7, 503-519. [CrossRef] [PubMed]

49. Deltas, C. Digenic inheritance and genetic modifiers. Clin. Genet. 2018, 93, 429-438. [CrossRef] [PubMed] 